Ação pedagógica e Educação Especial

\title{
AÇão Pedagógica e educaÇão especial: a sala de ReCURSos como PRIORIDADE NA OFERTA DE SERVIÇOS ESPECIALIZADOS ${ }^{1}$
}

PEDAGOGICAL ACTION AND SPECIAL EDUCATION: SPECIAL EDUCATION

RESOURCE ROOM AS PRIORITY IN OFFERING SPECIALIZED SERVICES

Claudio Roberto BAPTISTA²

RESUMO: o objetivo do presente texto é apresentar reflexões acerca da ação pedagógica e dos serviços especializados em Educação Especial, no contexto brasileiro. Busca-se dar destaque a um debate sobre as tendências, as características e os desafios que marcam a oferta de serviços educacionais, assim como a ação dos educadores especializados. A presente análise pretende contribuir para a compreensão sobre como ocorreram alterações políticas que resultam no avanço da sala de recursos como serviço prioritário para a política educacional brasileira no que se refere à garantia de Atendimento Educacional Especializado aos alunos com deficiência, transtornos globais do desenvolvimento e altas habilidades/superdotação. Quais são os desafios associados à sala de recursos como espaço escolar e como dispositivo pedagógico? Como os estudos contemporâneos têm se ocupado de analisar as recentes experiências no contexto nacional? Nestas reflexões são considerados: o fortalecimento da inclusão escolar como diretriz política para a educação brasileira; as indicações, em termos de documentos legais e orientadores, para a constituição dos serviços; o debate acadêmico quanto à necessidade de avanços na qualificação das salas de recursos, indicando a necessária difusão do conhecimento produzido e a intensificação de sua deriva pedagógica nas relações com o currículo e com a ação docente em geral.

PALAVRAS-CHAVE: Educação Especial. Serviços especializados. Sala de recursos. Inclusão escolar. ANPEd.

\begin{abstract}
The aim of this paper is to present reflections on the pedagogical action and specialized services in Special Education in Brazil. The aim is to discuss trends, characteristics and challenges that feature Brazilian educational services supply as well as the action of specialist teachers. This analysis aims to contribute to the understanding of how educational policies have changed and how these changes took the Special Education Resource Room to a priority service level in the Brazilian educational policy, regarding warranting specialized educational services for students with disabilities, pervasive developmental disorders and high ability/ giftedness. What are the challenges associated with the Special Education Resource Room as a school space and as a pedagogical device? How have contemporary studies been analyzing the recent experiences within the national context? The following aspects are considered in these reflections: the growth of educational inclusion as a guiding policy for Brazilian education; eligibility for service providing, in terms of legal documents and guidance; academic discussion on the need for advances in Special Education Resource Room's quality, indicating the necessary dissemination of the produced knowledge and the intensification of its pedagogical outcome in the relations with the educational curriculum and teaching activities in general.
\end{abstract}

KEYWORDS: Special Education. Specialized Services. Special Education Resource Room. Educational Inclusion. National Association of Post-Graduation and Research.

\section{INTRODUÇÃO}

Nos últimos 20 anos temos vivenciado, no Brasil, um fortalecimento da inclusão escolar como organizadora das metas para a escolarização das pessoas com deficiência, transtornos globais de desenvolvimento e altas habilidades/

\footnotetext{
${ }^{1}$ O presente trabalho foi realizado com o apoio da CAPES.

${ }^{2}$ Doutor em Educação pela Universidade de Bologna. Professor da Faculdade de Educação e do Programa de PósGraduação da UFRGS. Coordenador do NEPIE - Núcleo de Estudos em Políticas de Inclusão Escolar da UFRGS. Site: www.ufrgs.br/faced/pesquisa/nepie. Email: baptistacaronti@yahoo.com.br
} 
BAPTISTA, C. R.

superdotação ${ }^{3}$. Essa perspectiva exige que se institua um amplo debate sobre as diretrizes da escola brasileira, sua organização pedagógica e seus profissionais, no sentido de favorecer a pluralidade de ações que sejam complementares, articuladas e que garantam o acesso ao conhecimento, assim como a oferta de apoios demandados por um grande contingente de alunos.

O objetivo do presente texto é apresentar reflexões acerca da ação pedagógica $e$ dos serviços educacionais especializados dirigidos às pessoas com deficiência, considerando o contexto brasileiro contemporâneo e os desafios de proposições políticas que indicam a inclusão escolar como a diretriz para esse trabalho. Para essa análise, procurarei recorrer ao debate sobre as tendências, as características e os desafios que marcam a oferta de serviços educacionais, assim como a ação dos educadores especializados em Educação Especial ${ }^{4}$, resgatando aspectos constitutivos da história da Educação Especial brasileira.

No que se refere à forma que devem assumir as presentes reflexões, minha opção é baseada na exploração de uma temática, reunindo indícios do cotidiano e experiências já relatadas com vistas a uma sistematização de ideias na busca de elucidar sentidos e, assim, contribuir para a compreensão relativa ao atual momento da Educação Especial brasileira, suas práticas e seus espaços de ação.

Ao identificar indícios, destaco uma informação veiculada no portal do $\mathrm{MEC}^{5}$, em 2010:

A Secretaria de Educação Especial oferece equipamentos, mobiliários e materiais didático-pedagógicos e de acessibilidade para a organização das salas de recursos multifuncionais, de acordo com as demandas apresentadas pelas secretarias de educação em cada plano de ações articuladas (PAR). De 2005 a 2009, foram oferecidas 15.551 salas de recursos multifuncionais, distribuídas em todos os estados e o Distrito Federal, atendidos 4.564 municípios brasileiros - 82\% do total. (grifo meu)

Essa informação coloca em evidência uma ação institucional e mostra uma diretriz política para os serviços especializados. Entre os anos de 2005 e 2010, houve um grande investimento na sala de recursos como o espaço prioritário para a oferta do atendimento educacional especializado, assim como ocorreu o avanço do debate acerca das atribuições do professor que desenvolve esse trabalho. Os sentidos dessa ênfase podem ser identificados quando analisamos as políticas de Educação Especial no Brasil ao longo da última década, mas, no momento, quero colocar em confronto essa 'notícia' veiculada no portal do Ministério da Educação

\footnotetext{
${ }^{3}$ Embora a Política Nacional de Educação Especial na perspectiva da Educação Inclusiva de 2008 defina o alunado da educação especial como aqueles com deficiência, com transtornos globais de desenvolvimento e altas habilidades, utilizarei ao longo deste texto a expressão 'alunos com deficiência' para me referir a esse alunado, em função de sua prevalência numérica e da configuração de desafios associados aos serviços que apresentam características pedagógicas semelhantes àquelas relativas aos demais grupos de sujeitos.

${ }^{4}$ Estou considerando educador especializado em educação especial ou educador especial aquele com formação específica: curso de graduação na área; em pedagogia, com habilitação específica; curso de especialização ou estudos complementares. Essa pluralidade de dimensões quanto à formação é garantida pela legislação atual, a qual não define especificamente uma trajetória.

${ }^{5}$ Acesso: http:/ / portal.mec.gov.br/index.php?option=com_content\&view=article\&id=12295\&Itemid=595
} 
com um texto que anunciava as metas para a Educação Especial e para os serviços especializados, em 1993, momento em que estava em discussão a Política Nacional de Educação Especial de 1994:

Pelos menos uma classe para a Educação Especial em cada escola é o nosso lema. (CARVALHO, 1993, p. 95, grifo meu)

Trata-se de um texto da então Secretária de Educação Especial do Ministério da Educação, Prof ${ }^{a}$ Rosita Carvalho, apresentando a Política Nacional de Educação Especial de 1994. Um dos aspectos importantes a serem destacados é que a 'classe' referida na citação é a classe especial. Era um momento histórico no qual já havia muita reflexão crítica acerca da classe especial e dos riscos em termos de afastamento do ensino comum de alunos que não apresentavam deficiências, mas dificuldades escolares associadas a uma escola que continuava selecionando os 'aptos' (FERREIRA; NUNES, 1993). Embora já fossem discutidas, no contexto brasileiro, as vantagens e a importância da inclusão escolar, designada como integração, em 1993 os serviços de atendimento exclusivo - classes especiais e escolas especiais - eram reconhecidos como imprescindíveis ao trabalho pedagógico nessa área.

Ao longo dos últimos 18 anos, identifica-se uma significativa mudança quanto às diretrizes, em função da aprovação da Política Nacional de Educação Especial na perspectiva da Educação Inclusiva em 2008, , seguida de dispositivos normativos como a Resolução 04/2009 do CNE-CEB, os quais reafirmam o caráter da Educação Especial como ação complementar ou suplementar e não mais substitutiva à escolarização no ensino comum, como ocorria em classes e escolas especiais. Em momento posterior, retomarei esses dispositivos orientadores ou normativos para identificação dos possíveis efeitos quanto à configuração dos serviços especializados. Em função dessas diretrizes, a sala de recursos assume um protagonismo que pode ser justificado por suas características. Para buscar a compreensão acerca de como se institui esse protagonismo na política educacional brasileira relativa à Educação Especial e à inclusão escolar, será importante dirigirmos nossa atenção para iniciativas e deslocamentos que envolveram os sujeitos partícipes, com particular atenção voltada para os gestores em diferentes instâncias.

Restam muitas perguntas relativas aos direcionamentos das novas metas dirigidas aos serviços especializados: como compreender essa mudança? A quem se destina, de fato, o espaço pedagógico da sala de recursos? Como deve ser constituída essa sala, considerando que se trata de espaço escolar e de um dispositivo pedagógico? Que características deve ter o docente para atuar nessas salas? Quais são os pressupostos implicados na valorização da sala de recursos como o espaço prioritário para o apoio especializado aos alunos com deficiência? Quais são as metas para o trabalho docente nesses espaços e suas conexões com o ensino realizado nas salas comuns? São muitas as interrogações possíveis.

${ }^{6}$ Uma reflexão sistematizada sobre os sentidos históricos desse documento orientador é apresentada em Baptista (2008). 
BAPTISTA, C. R.

Considero que um dos objetivos do presente texto é contribuir para a elaboração de algumas dessas respostas, sem a pretensão de abordar em modo conclusivo a temática e reconhecendo a complexidade que se apresenta no debate. Para dar continuidade à análise, buscarei alguns elementos históricos que nos ajudam a vislumbrar como chegamos às atuais propostas de organização de serviços.

\section{Breves reflexões sobre a história e a política de Educação Especial no Brasil}

Quando consideramos a Educação Especial e sua prática pedagógica, devemos reconhecer que essa ação depende de um contexto institucional representado pelas escolas e por seus objetivos. Nesse sentido, a década inicial no presente século pode ser considerada um marco no que refere ao estabelecimento desses objetivos quanto se trata da escolarização das pessoas com deficiência. Desde 2001, com a aprovação da Res. nº 02/2001 CNE-CEB, temos visto, de um lado, o avanço de dispositivos normativos que passam a prever que essa escolarização deva ocorrer necessariamente no ensino comum. De outra parte, nessa mesma década, houve uma série de iniciativas que visavam à implementação de políticas de educação em uma perspectiva de ampliação dos sujeitos a serem escolarizados na escola regular. Dentre essas ações, várias foram aquelas que evidenciavam as iniciativas do Ministério da Educação na busca de interlocução com os gestores, principalmente em nível municipal, para a garantia de ações consideradas 'inclusivas'. Nessa direção, a Secretaria de Educação Especial do MEC implementou um Programa que visava à difusão de sistemas inclusivos por meio da formação e da gestão - o Programa Educação Inclusiva: Direito à Diversidade (2003-2010). Esse programa intensificou a relação entre SEESP e uma rede de municípios-pólo nos diferentes estados, tendo efeitos que ainda carecem de maiores análises. No caso do Rio Grande do Sul, considero que Brizolla (2007) sistematiza importantes reflexões sobre os desdobramentos desse programa, considerado um instrumento de gestão, no que se refere à análise de 10 municípios-pólo desse estado ${ }^{7}$. Alguns dos efeitos investigados por essa autora dizem respeito à instituição de núcleos de gestão de Educação Especial, nos municípios, assim como o aumento de oferta do atendimento educacional especializado pelos sistemas públicos e intensificação da presença de alunos com deficiência nos espaços do ensino comum ${ }^{8}$.

Em 2008, a Política Nacional de Educação Especial na perspectiva da Educação Inclusiva contribuiu para a intensificação do debate e delineou as diretrizes orientadoras para a política brasileira para a área, afirmando um grupo específico de sujeitos prioritários da ação da Educação Especial, já referidos no início deste texto, além de destacar a sala de recursos como lócus prioritário do trabalho

\footnotetext{
${ }^{7}$ Ainda com relação ao Rio Grande do Sul, o NEPIE - Núcleo de Estudos em Políticas de Inclusão Escolar da UFRGS desenvolve um projeto, no âmbito do Programa CAPES-PROESP, intitulado Políticas de Educação Especial e Inclusão Escolar: Sujeitos, Práticas Pedagógicas e Serviços. A análise dos serviços especializados em 14 municípios gaúchos com posição estratégica em suas regiões de pertencimento é uma das metas do projeto.

${ }^{8}$ Trata-se de um fenômeno amplamente descrito em contextos muito diversificados, como é possível analisar em Baptista e Jesus (2009).
} 
específico da Educação Especial. Houve, por meio desse documento, a indicação de que o atendimento educacional especializado não deveria substituir, mas complementar ou suplementar, o ensino em classes comuns. A Resolução 04/2009 do CNE-CEB surge como um dos dispositivos que conferem operacionalidade à Política, pois define as diretrizes do atendimento educacional especializado, delimitando quais instituições podem oferecê-lo e como esse oferecimento deve ser um suporte à presença do aluno nas escolas regulares. Esta ênfase no contexto escolar comum altera o plano normativo da política educacional brasileira para a Educação Especial, pois abandona-se o discurso da excepcionalidade da escolarização em espaços exclusivamente especializados - classes especiais e escolas especiais (KASSAR; REBELO, 2011).

Desse modo, tem sido afirmada, no Brasil, a determinação legal de que a escolarização de todas pessoas com deficiência deve ocorrer no ensino comum. Tratase de consideração facilmente aceita quando examinamos os dispositivos legais do período posterior à publicação da Política Nacional de Educação Especial de 2008, como as Resoluções 04/2009 CNE-CEB e 04/2010 CNE-CEB.

A Política Nacional de Educação Especial na perspectiva da Educação Inclusiva de 2008 tem no Decreto $n^{\circ} 6.571$ de setembro de 2008 um ponto de apoio operacional, em função de seu caráter regulador da distribuição dos recursos.

O Parecer no 13/2009 do CNE-CEB visa à regulamentação do referido Decreto, o qual define o uso de recursos do FUNDEB, com base nos dados obtidos pelo INEP/Censo escolar, que podem ser direcionados para o atendimento educacional especializado, garantindo a contagem dupla de matrícula - ensino especial e ensino comum - para o aluno com deficiência. Considero necessário atentar, portanto, às palavras que constituem esse parecer:

\begin{abstract}
ODecreto $^{\circ}$ 6.571/2008, que dispõe sobre o atendimento educacional especializado, regulamenta o parágrafo único do art. 60 da Lei $n^{\circ}$ 9.394/96, e acrescenta dispositivo ao Decreto $\mathrm{n}^{\circ} 6.253$, de 13 de novembro de 2007, estabelecendo que:

Art. $1^{\circ}$ A União prestará apoio técnico e financeiro aos sistemas públicos de ensino dos Estados, do Distrito Federal e dos Municípios, na forma deste Decreto, com a finalidade de ampliar a oferta do atendimento educacional especializado aos alunos com deficiência, transtornos globais do desenvolvimento e altas habilidades ou superdotação, matriculados na rede pública de ensino regular.

$\S 1^{\circ}$ Considera-se atendimento educacional especializado o conjunto de atividades, recursos de acessibilidade e pedagógicos organizados institucionalmente, prestado de forma complementar ou suplementar à formação dos alunos no ensino regular.

$\S 2^{\circ} \mathrm{O}$ atendimento educacional especializado deve integrar a proposta pedagógica da escola, envolver a participação da família e ser realizado em articulação com as demais políticas públicas. (Parecer nº 13/2009 do CNE-CEB, grifos meus)
\end{abstract}

O Parecer é seguido da Resolução que institui as diretrizes operacionais para o atendimento educacional especializado - a Resolução 04/2009 do CNE-CEB - a qual tem como artigo inicial a indicação: 
BAPTISTA, C. R.

Art. $1^{\circ}$ Para a implementação do Decreto $n^{\circ} 6.571 / 2008$, os sistemas de ensino devem matricular os alunos com deficiência, com transtornos globais do desenvolvimento e com altas habilidades/superdotação em classe comum de escola de ensino regular $e$ no Atendimento Educacional Especializado (AEE), ofertado em salas de recursos multifuncionais ou centros de Atendimento Educacional Especializado da rede pública ou de instituições comunitárias, confessionais ou filantrópicas sem fins lucrativos. (grifos meus)

Esta resolução define o alunado que é público-alvo para o atendimento educacional especializado (AEE), além de apresentar detalhamento relativo aos diferentes aspectos que integram as prioridades. $\mathrm{O}$ art. $8^{\circ}$ indica que "serão contabilizados duplamente, no âmbito do FUNDEB, de acordo com o Decreto $\mathrm{n}^{\circ}$ $6.571 / 2008$, os alunos matriculados em classe comum do ensino regular público que tiverem matrícula concomitante no AEE". Em seguida, no mesmo artigo, encontra-se a afirmação: "O financiamento da matrícula no AEE é condicionado à matrícula no ensino regular da rede pública, conforme registro no Censo escolar/ MEC/INEP do ano anterior...". Para além desse pressuposto vinculador, o texto da resolução indica que é de competência dos professores que "atuam na sala de recursos multifuncionais ou centros de AEE" a elaboração e execução do "plano do AEE", em articulação com os demais professores do ensino regular. Percebese, portanto, a necessidade de planejamento e de articulação entre educação especializada e ensino comum.

No que se refere à formação do professor responsável pelo AEE, as indicações da referida resolução são bastante genéricas: "o professor deve ter formação inicial que o habilite para o exercício da docência e a formação específica para a Educação Especial" (Art. 12). Pode-se supor que essa formação específica será bastante diversificada, considerando as potencialidades de formação e os quadros existentes nos diferentes estados brasileiros.

Quanto às diretrizes para a ação desses profissionais, o Art. 13 indica que são atribuições do professor do Atendimento Educacional Especializado:

I - identificar, elaborar, produzir e organizar serviços, recursos pedagógicos, de acessibilidade e estratégias considerando as necessidades específicas dos alunos público-alvo da Educação Especial;

II - elaborar e executar plano de Atendimento Educacional Especializado, avaliando a funcionalidade e a aplicabilidade dos recursos pedagógicos e de acessibilidade;

III - organizar o tipo e o número de atendimentos aos alunos na sala de recursos multifuncionais;

IV - acompanhar a funcionalidade e a aplicabilidade dos recursos pedagógicos e de acessibilidade na sala de aula comum do ensino regular, bem como em outros ambientes da escola;

$\mathrm{V}$ - estabelecer parcerias com as áreas intersetoriais na elaboração de estratégias e na disponibilização de recursos de acessibilidade;

VI - orientar professores e famílias sobre os recursos pedagógicos e de acessibilidade utilizados pelo aluno;

VII - ensinar e usar a tecnologia assistiva de forma a ampliar habilidades funcionais dos alunos, promovendo autonomia e participação; 
VIII - estabelecer articulação com os professores da sala de aula comum, visando à disponibilização dos serviços, dos recursos pedagógicos e de acessibilidade e das estratégias que promovem a participação dos alunos nas atividades escolares. (grifos meus)

Embora tenhamos que admitir a grande amplitude das ações e a possibilidade interpretativa de práticas centradas no atendimento direto ao aluno, é necessário que se identifique a potencial valorização do trabalho compartilhadocom outros profissionais, principalmente o docente do ensino comum, como indicam os incisos IV, VI e VIII. São ainda tímidas as indicações apresentadas pela Resolução 04/2009 do CNE quanto a essa mudança de perspectiva que valoriza uma ação mais sistêmica do educador especializado? Possivelmente, sim. No entanto, para que se trabalhe no sentido de tornar viável essa mudança, será necessário que avancemos no debate contemporâneo que associa as diretrizes da Educação Especial àquelas da educação, que reconheçamos a necessidade de utilizar os recursos disponíveis, propondo que haja um refinamento de nossas práticas aliado à capacidade de gestão. É necessário que se diga, no entanto, que este contexto de mudanças potenciais mostra a importância do professor especializado em Educação Especial para que se garanta a existência de percursos escolares satisfatórios e desafiadores para os alunos com deficiência. Essa importância respalda-se na centralidade da sala de recursos como o dispositivo pedagógico prioritário na política de Educação Especial contemporânea, considerada sua característica de não substituição do espaço da sala de aula comum para a escolarização. Além disso, as atribuições que implicam conexões/articulações entre o docente especializado e o professor do ensino comum abrem espaço para a discussão curricular necessária nos processos inclusivos. O quê devemos ensinar? Como devem estar organizadas nossas práticas? Que características devem ter nossos procedimentos avaliativos? E tantas outras questões... Considero necessário, portanto, uma breve análise da sala de recursos como dispositivo pedagógico, seu surgimento no contexto brasileiro e suas perspectivas anunciadas em estudos recentes.

\section{A sala de recursos}

A sala de recursos é um dispositivo previsto na Educação Especial brasileira, mas pouco utilizado até meados da primeira década deste novo século. Para termos clareza acerca de suas características e de sua historicidade, atentemos às palavras de Mazzotta (1982):

a sala de recursos, como o ensino itinerante, é uma modalidade classificada como auxílio especial. Como o próprio nome diz, consiste em uma sala da escola, provida com materiais e equipamentos especiais, na qual um professor especializado, sediado na escola, auxilia os alunos excepcionais ${ }^{9}$ naqueles aspectos específicos em que precisam de ajuda para se manter na classe comum. O professor da sala de recursos tem uma dupla função: prestar atendimento direto ao aluno e indireto através de orientação e assistência aos professores da classe comum, às

\footnotetext{
${ }^{9}$ Termo utilizado naquele momento histórico.
} 
BAPTISTA, C. R.

famílias dos alunos e aos demais profissionais que atuam na escola. Mediante esta modalidade de atendimento educacional, o aluno é matriculado na classe comum correspondente ao seu nível de escolaridade. Assim sendo, o professor especializado deve desenvolver o seu trabalho de forma cooperativa com os professores de classe comum. ( p. 48).

Como podemos perceber, as linhas organizadoras desse espaço escolar, segundo as palavras desse autor, não se referem exclusivamente ao trabalho direto com o aluno com deficiência e constituem uma ação complexa, articulada, de múltiplas interferências. A importância desses destaques é uma decorrência da percepção de que a pluralidade de ações previstas para o educador especializado nem sempre esteve presente nas propostas que caracterizam a sala de recursos. Vivemos, continuamente, a tensão que tende a restringir essas práticas a um conjunto instrucional de procedimentos, apesar de termos algumas propostas que merecem atenção e análise relativa a seus efeitos.

Quando analisamos os estudos que investigam a sala de recursos no contexto brasileiro, temos algumas regularidades de publicações, como aquelas que têm como foco a realidade das redes municipais da cidade de São Paulo (PRIETO; SOUZA, 2007) e da cidade de Porto Alegre (TEZZARI, 2002). Prieto analisa, em diversas publicações, as SAPNEs (Salas de Atendimento aos Portadores de Necessidades Especiais), que ofereciam atendimento complementar ou exclusivo aos alunos. Segundo Prieto e Souza (2007), tais salas, em 2004, passaram a ser designadas Salas de Apoio e Acompanhamento à Inclusão (SAAIs) e reduziram drasticamente o caráter substitutivo à escolarização do atendimento oferecido aos alunos. Tezzari (2002) analisa as SIRs (Salas de Integração e Recursos) que atuam em modo necessariamente complementar e propõem uma articulação entre a ação direta do atendimento ao aluno com aquela de acompanhamento e assessoria ao docente do ensino comum. As singularidades desses serviços, as trajetórias dos alunos, as percepções dos profissionais envolvidos têm sido alguns dos eixos que orientam as referidas pesquisas. Em ambos os casos, observa-se o destaque quanto à potencialidade do atendimento em sala de recursos como um suporte que tende a contribuir para a permanência do aluno no ensino comum, assim como ocorre o destaque acerca da necessidade de investimentos na qualificação desses espaços, principalmente no que se refere às possíveis articulações entre as ações do educador especializado e aquelas do professor de sala aula comum. Quanto às origens desses serviços nas duas capitais, pode-se observar pontos de coincidência que envolvem um momento histórico semelhante, pois em Porto Alegre a SIR surgiu como um projeto em 1995 e passou a ser um serviço em 1997 (TEZZARI, 2002) e em São Paulo o surgimento da SAPNE, como um serviço, é associado ao ano de 1993 (PRIETO; SOUZA, 2007). Outro aspecto que aproxima as duas propostas é a diretriz política da educação municipal, pois o avanço desses serviços ocorreu, nos dois municípios, em gestões vinculadas ao Partido dos Trabalhadores. Tal fenômeno foi reafirmado em nível nacional, visto que a disseminação da sala de recursos como serviço prioritário da Educação Especial começou a ter ênfase durante o governo do Presidente Lula 
da Silva, após 2005 em modo mais intenso. Um ulterior ponto de aproximação entre as propostas de SIR e SAPNE é associado aos procedimentos de ingresso dos alunos nos serviços. Prieto, Souza e Silva (2006) enfatizam que o encaminhamento do aluno para esse serviço parece ser uma decisão que envolve a professora da classe regular em parceria com a professora da SAPNE, sem o apoio de laudos psicológicos ou médicos. Este procedimento está em sintonia com aquele descrito por Tezzari (2002) relativo a Porto Alegre. Em ambos os casos, chama atenção a ênfase na avaliação pedagógica para a decisão de encaminhamento. Considero que se trata de um avanço o fortalecimento da responsabilidade dos educadores, principalmente aqueles especializados, no processo desse diagnóstico inicial para o acesso à sala de recursos. No entanto, há riscos que são associados à possibilidade de encaminhamento de alunos com dificuldades de aprendizagens decorrentes dos processos de ensino que não são flexibilizados. Evidentemente, a saída para evitar esses riscos não se encontra na defesa do diagnóstico clínico, pois, mesmo com a existência desses diagnósticos, os equívocos de encaminhamento constituem algo comum na educação especializada no Brasil.

No que se refere à definição do serviço, em Porto Alegre, Tezzari e Baptista (2002) afirmam que a SIR é:

(...) um espaço paralelo de atendimento, em um turno inverso àquele no qual o aluno freqüenta a classe comum. Os alunos atendidos passam por uma triagem pedagógica que identifica a necessidade de uma ação especifica e complementar, a ser desenvolvida por um profissional da educação especial. Há ênfase em atividades alternativas àquelas desenvolvidas em sala de aula, partindo-se dos recursos apresentados pelo sujeito. ( p 146)

Uma análise relativa aos sentidos da frequência à SIR, atribuídos pelos alunos, foi apresentada por Schneider e Passerino (2010), na qual as autoras destacam a percepção de uma dimensão lúdica associada à aprendizagem, assim como os riscos de um espaço que pode sinalizar as diferenças que hierarquizam os alunos na escola. Tais reflexões nos alertam para um risco que se associa à frequência a serviços especializados: ter acesso ao apoio e conviver com a marca daquele que necessita de apoio.

Outros estudos têm sido realizados em diferentes municípios brasileiros, analisando as salas de recursos. Tais investigações reafirmam a importância desse serviço especializado no apoio ao aluno com deficiência que frequenta o ensino comum. Trata-se de aspecto destacado por Oliveira (2004), em análise que tomou como referência o contexto do município de Campo Grande (MS) e as salas de recursos destinadas aos alunos com deficiência mental. Ainda considerando Campo Grande, a investigação de Corrêa (2011) destaca as questões relativas ao financiamento associadas à implementação das salas de recursos. Bürkle (2010) investigou as salas de recursos no município do Rio de Janeiro. Segundo essa autora, "a pesquisa constatou a viabilidade e importância do trabalho realizado nesses espaços, pois eles representam efetivos instrumentos de inclusão no sistema educacional" (BÜRKLE, 2010, p. 123). Essa compreensão está em sintonia com as 
BAPTISTA, C. R.

premissas apresentadas por Santos Júnior (2002), Tezzari (2002), Arnal e Mori (2007), Barreto e Goulart (2008), Silva (2010), reafirmando a potência que se associa a um espaço pedagógico que congrega a ação de um educador especializado, oferecendo apoio ao aluno com deficiência e ao sistema de ensino no qual o aluno está inserido.

As singularidades associadas à formação do educador especializado são analisadas por Silva e Monteiro (2009) ao considerarem o professor que atua em sala de recursos a partir de pesquisa realizada em escolas estaduais do Mato Grosso, nos municípios de Cuiabá e Várzea Grande.

Tais singularidades e as exigências de formação qualificada continuam integrando um debate nacional que prevê grandes responsabilidades para um serviço que tem no profissional que o representa seu principal 'recurso' ou 'instrumento'. Como se trata de um processo de instituição de serviços, com base na ação de profissionais que possuem trajetórias bastante diferenciadas - formação recente em Educação Especial ou trabalho precedente em classes especiais e escolas especiais -, considero imprescindível que sejam garantidos espaços de formação continuada para que tais profissionais possam confrontar suas dúvidas e seus conhecimentos (ALMEIDA, 2011). Essa dinâmica de constituição e de formação é analisada por Delevati (2011), no município de Gravataí, no Rio Grande do Sul. Como ocorre com muitos municípios brasileiros, Gravataí teve um aumento acelerado de salas de recursos nos últimos anos, fazendo com que o número desses serviços passasse de quatro, em 2008, para 30 no início de 2011, em uma rede com 66 escolas de ensino fundamental ${ }^{10}$.

A atividade de atendimento complementar em salas de recursos é ainda analisada por Soares (2011) no que diz respeito à escolarização de alunos com surdez, no ensino médio comum, em Gravataí. O autor destaca a articulação entre diferentes alternativas de apoio oferecidas aos alunos em escola da rede municipal.

A relação entre Educação Especial e educação infantil constitui um ponto de necessário investimento pela escassez de serviços e pela importância dos apoios em momento inicial da vida e da escolarização das crianças com deficiência. Essa temática é abordada por Benincasa (2011) que analisa um serviço de Educação Especial - Educação Precoce e Psicopedagogia Inicial - dirigido aos alunos da educação infantil na Rede Municipal de Ensino de Porto Alegre, procurando compreender a singularidade dessas práticas. Ainda no contexto do município de Porto Alegre, Freitas (2011) investigou as crianças identificadas como aquelas 'que não param' acompanhadas pelos referidos serviços de apoio às crianças da educação infantil, analisando a produção desses sujeitos e o lugar da educação como área implicada nos processos de identificação e atendimento dirigido aos alunos considerados hiperativos.

\footnotetext{
${ }^{10}$ Em função das atividades de investigação do Projeto Políticas de Educação Especial e Inclusão Escolar: Sujeitos, Práticas Pedagógicas e Serviços, temos acesso a informações de outros municípios do Rio Grande do Sul, as quais mostram que a tendência dos serviços especializados é de fechamento das classes especiais e abertura das salas de recursos. Tais salas têm mostrado aumento expressivo em cidades como Santa Maria, Pelotas e Porto Alegre.
} 
Ao referir pesquisas desenvolvidas na UFRGS, desejo explicitar um campo reflexivo que orienta a presente sistematização de ideias. Mesmo que não sejam evocados, em detalhes, aspectos específicos dessas investigações, há um contínuo diálogo com os eixos que as orientam: relação educação comum e Educação Especial; práticas que se traduzem em atendimento, em dinâmicas de assessoria e formação de outros profissionais; a presença no ensino comum como evidência da aposta radical na educabilidade dos sujeitos com deficiência.

Muitos dos estudos citados colocam em evidência as redes municipais de educação. Quando analisamos o âmbito municipal da gestão das políticas públicas relativas à Educação Especial, é necessário reconhecer que, em muitos municípios, tem ocorrido um processo de sintonia com a diretriz de oferta das salas de recursos por meio da adesão a programas, como aquele que oferece os materiais para esse tipo de serviço ${ }^{11}$. Essa adesão é apenas um início de um processo laborioso de instituição dos serviços, pois cabe ao município contratar os profissionais qualificados ou investir na formação de integrantes de seus quadros, além do delineamento pedagógico que deverá inserir esses serviços nos projetos político-pedagógicos das escolas. No entanto, é fundamental admitir que hoje, além da exigência legal de oferta da escolarização no ensino comum, há elementos associados à distribuição de recursos que tendem a fazer com que os gestores invistam em serviços de atendimento complementar. Para isso, os profissionais qualificados devem continuar atuando na rede, fenômeno que deverá alterar a histórica 'tradição' das cedências de profissionais integrantes dos sistemas públicos de ensino, com formação em Educação Especial, para atuarem em instituições especializadas e filantrópicas.

Trata-se, apenas de um começo. Os desafios são imensos, pois devemos qualificar os sistemas de ensino para essa ação, em sintonia com a busca de oferecimento de serviços de qualidade para os diferentes planos da ação pedagógica: ampliar e qualificar a educação infantil, garantir a aprendizagem e a continuidade nos ciclos iniciais do ensino fundamental, reduzir o acentuando declínio na passagem ao ensino médio, escolarizar aqueles que não tiveram formação compatível com as idades previstas, ampliar o acesso ao ensino superior, assegurar a presença de apoio qualificado aos processos de inclusão escolar...

\section{CONSIDERAÇÕES FINAIS}

Ao longo do presente texto, procurei colocar em destaque os movimentos identificáveis no contexto brasileiro relativos à inclusão escolar e à Educação Especial na última década, com ênfase nos aspectos diretamente atinentes à oferta de serviços especializados e à gestão das políticas públicas na busca de 'tradução' desses serviços como dispositivos para a consolidação da garantia de atendimento educacional especializado aos alunos com deficiência no ensino comum. Além

\footnotetext{
${ }^{11}$ Refiro-me ao Programa de Implantação de Salas de Recursos Multifuncionais, do Ministério da Educação, instituído por meio da Portaria Ministerial nº 13/2007.
} 
BAPTISTA, C. R.

disso, busquei sinalizar as regularidades e os pontos de tensão presentes nos recentes estudos que têm se ocupado da sala de recursos como uma temática prioritária de investigação.

Com relação aos estudos que analisam a sala de recursos, no contexto brasileiro, podemos afirmar que não são muito numerosos. O motivo é simples: não se pode investigar algo que não existe. Se há poucos estudos é porque a existência desses espaços esteve restrita a alguns contextos. O histórico investimento em classes especiais e em escolas especiais reduzia a suposta necessidade de sala de recursos. O incremento numérico dessas salas deverá provocar novas pesquisas que nos mostrarão como têm sido 'interpretadas' as diretrizes para tais dispositivos. Portanto, a pesquisa vinculada à sala de recursos é uma meta para o futuro. Além disso, não considero que seja uma responsabilidade da investigação científica determinar 'se' sala de recursos, mas a pesquisa poderá nos indicar 'como' sala de recursos. Ao considerarmos que um contexto estimulante e exigente é um bom disparador de processos de aprendizagem em geral, devemos reconhecer que os alunos com deficiência estarão em melhores condições se frequentarem o ensino comum, com a complementação do apoio especializado. Esse apoio deve auxiliar na exploração de alternativas diferenciadas de acesso ao conhecimento, inserindo, inclusive, dinâmicas que permitam utilizar seus recursos potenciais, aprender novas linguagens, desenvolver a capacidade de observar e de auto observar-se. Algumas das vantagens que eram associadas à classe especial podem ser potencializadas na sala de recursos, pois o trabalho com pequenos grupos é estimulado, permitindo melhor acompanhamento do aluno, favorecendo trajetórias de aprendizagem mais individualizadas sob a supervisão de um docente com formação específica. No caso da sala de recursos, a grande vantagem é que esse processo tem condições de alternância contínua com aquele desenvolvido na sala de aula comum.

Como foi enfatizado ao longo do presente texto, as políticas brasileiras para a Educação Especial mostram que temos uma evidência: a sala de recursos tem sido destacada como o espaço prioritário para a ação do educador especializado em Educação Especial. Sua dimensão 'multifuncional', designação proposta pelo Ministério da Educação ao instituir um programa, referido em precedência, de oferta de materiais destinados às redes de ensino, merece ainda algum destaque. Multifuncional em função de qual justificativa? A pluralidade de funções estaria associada às diferentes tipologias de alunos que teriam acesso a esse espaço? A resposta tende a ser afirmativa quando analisados os dois conjuntos de materiais, oferecidos pelo programa, das salas de tipo 1 e de tipo 2 , sendo que a diferenciação estaria na deficiência visual (tipo 2) e demais sujeitos (tipo 1).

A sala de recursos multifuncionais é, portanto, um espaço organizado com materiais didáticos, pedagógicos, equipamentos e profissionais com formação para o atendimento às necessidades educacionais especiais. (....) A denominação sala de recursos multifuncionais se refere ao entendimento de que esse espaço pode ser utilizado para o atendimento das diversas necessidades educacionais especiais e para desenvolvimento das diferentes complementações ou suplementações curriculares. (ALVES, 2006, p. 14). 
Portanto, penso que exista uma outra dimensão evocada com o termo multifuncional que merece ser abordada em nossos questionamentos. Multifuncional porque pode favorecer ou instituir uma pluralidade de ações que variam desde o atendimento direto ao aluno, ou a grupos de alunos, até uma ação em rede. Refiro-me ao acompanhamento de processos que ocorrem nas salas de aula comum, na organização de espaços transversais às turmas, em projetos específicos, na assessoria a colegas docentes, em contatos com familiares ou outros profissionais que têm trabalhado com os alunos. Para fazermos essa leitura da dimensão multifuncional, devemos deslocar nosso olhar da sala de recursos como um espaço físico e vislumbrá-lo como um espaço institucional necessariamente respaldado em um profissional que o representa: o educador especializado. Essa fusão educador/espaço escolar era já evocada no título do trabalho de Tezzari (2002), no qual a autora destacava uma fala de colegas docentes "A SIR chegou...". A Sala de Integração e Recursos (SIR) era, nesta fala, sinônimo de uma pessoa e de um profissional. Se a 'SIR' havia chegado a algum lugar, esse lugar não era o espaço físico de suposta centralidade de seu trabalho de atendimento aos alunos, mas evocava um deslocamento para outros espaços da escola. Duas pontuações, no entanto, precisam ser feitas: podemos falar em sala com funções plurais, sem que todas as ações sejam desenvolvidas por um único profissional. Uma sala de recursos pode concentrar a ação de mais de um educador especializado. Além disso, considero que um dos avanços relativos à formação desses educadores é o reconhecimento de que, apesar da necessidade de conhecimentos acerca de instrumentos, códigos e linguagens, o conhecimento geral acerca da educação e da Educação Especial deveria ser aquele primordial na formação do educador das pessoas com deficiência. Partindo dessa premissa, pode-se prever o acúmulo de conhecimentos específicos associados a determinados grupos de sujeitos, como aqueles com deficiência física, visual ou auditiva. $O$ inverso nem sempre é verdadeiro, pois não há garantias de que alguém que tenha um saber especializado muito restrito em uma tipologia de deficiência possua o conhecimento pedagógico que é exigido atualmente no trabalho que deve saber articular as singularidades do sujeito e os desafios da ação pedagógica no ensino comum. Trata-se, definitivamente, de uma mudança de perspectiva que envolve a opção por espaços educacionais e por alternativas de ação para o professor especializado.

Para concluir, considero que o debate sobre os serviços que oferecem o atendimento educacional especializado no Brasil deva, necessariamente, contemplar o contexto político educacional, no qual emergem proposições que se diferenciam das diretrizes históricas para os serviços de Educação Especial. É necessário reconhecer que, além das diretrizes gerais para a organização das salas de recursos, é fundamental garantir espaço de criação de delineamentos para esse serviço em função de características específicas de cada contexto. Devemos considerar a história recente de experiências que precederam a proposição de salas de recursos multifuncionais, algumas delas discutidas ao longo do presente texto. 
BAPTISTA, C. R.

A ênfase em um serviço não deveria ser confundida com a defesa de um modelo único para o país.

Apesar de reconhecer que há mudanças importantes em curso e que as diretrizes reinventadas por cada um dos núcleos gestores relativos aos sistemas de ensino têm condições de construir propostas que possam alterar o futuro da educação das pessoas com deficiência no Brasil, admito que temos um longo percurso a ser cumprido. Restam questionamentos muito importantes relativos: aos processos de identificação dos alunos que devem ter acesso a esses serviços; à etapa escolar considerada prioritária, pois temos presenciado uma ênfase no primeiro ciclo do ensino fundamental como o espaço de concentração das salas de recursos; à tendência de negação da complexidade dos fenômenos que caracterizam a vida escolar e valorização de uma premissa de 'ajuste' de 'correção' de um sujeito/ aluno... Nossas dificuldades primeiras, e possivelmente mais significativas, encontram-se no plano do cotidiano, de nossa capacidade de agir em modo sintônico com os atuais desafios que caracterizam a vida de cada professor. Talvez seja necessário reconhecermos que toda aprendizagem complexa exige ação como motor primordial. Essa afirmação que permeava as propostas de um estudioso como Celestin Freinet ainda está longe de integrar nossa capacidade de ensinar e aprender. Na Educação Especial essa afirmação ganha uma relevância extrema, em função das dinâmicas associadas à preparação contínua que impede que a 'grande promessa' da aprendizagem se cumpra. Estar preparado para aprender... Estamos sempre preparados, dependendo daquilo que é reconhecido pelo educador como 'aprendizagem'. Trata-se, portanto, de valorizarmos o conhecimento que já existe sobre processos de aprender e ensinar, evitando qualquer cisão simplificadora que separe o aluno com deficiência de seus companheiros de mesma idade.

\section{REFERÊNCIAS}

ALMEIDA, M. L. A contribuição da pesquisa-ação para os modos de conceber/ fazer a formação e a prática do professor do Atendimento Educacional Especializado. In: SEMINÁRIO NACIONAL DE PESQUISA EM EDUCAÇÃO ESPECIAL. Prática Pedagógica na Educação Especial: multiplicidade do atendimento educacional especializado, 4., 2011, Nova Almeida. Anais... Nova Almeida, 2011. 1 CD-ROM.

ALVES, D. O. Sala de recursos multifuncionais: espaços para atendimento educacional. Brasília. Ministério da Educação, Secretaria de Educação Especial, 2006. 36 p.

ARNAL, L. S. P.; MORI, N. N. R. Educação Escolar Inclusiva: A prática Pedagógica nas Salas de Recursos. In: CONGRESSO BRASILEIRO MULTIDISCIPLINAR DE EDUCAÇÃO ESPECIAL, 4., 2007, Londrina. Anais... Londrina: UEL, 2007.

BAPTISTA, C. R. A Política Nacional de Educação Especial no Brasil: passos para uma perspectiva inclusiva? In: MARTINS, L. et al. (Org.). Práticas inclusivas no sistema de ensino e em outros contextos. Natal: EDUFRN, 2008. p.19-33.

. JESUS, D. (Org.). Avanços em políticas de inclusão: o contexto da educação especial no Brasil e em outros países. Porto Alegre: Mediação, 2009. 
BARRETO, L. C. D.; GOULART, A. M. P. L. Educação geral ou especial? Um foco na sala de recursos. Educação em Revista, Marília v.9, n.2, p. 93-112, 2008.

BENINCASA, M. C. Educação Especial e Educação Infantil: uma análise de serviços de apoio especializado no município de Porto Alegre. 2011. 136f. Dissertação (Mestrado em Educação) - Faculdade de Educação, Programa de Pós-Graduação em Educação, Universidade Federal do Rio Grande do Sul, Porto Alegre, 2011.

BRASIL. Conselho Nacional de Educação. Câmara de Educação Básica. Resolução CNE/ CEB n. ${ }^{\circ}$ 02, de 11 de setembro de 2001. Diretrizes Nacionais para a Educação Especial na Educação Básica. Diário Oficial da União, 14 de setembro de 2001.

. Decreto n ${ }^{\circ} 6.571$, de 17 de setembro de 2008. Diário Oficial da União, 18 de setembro de 2008.

. Ministério da Educação. Secretaria de Educação Especial. Política Nacional de Educação Especial na perspectiva da educação inclusiva. Brasília, DF, 2008.

. Conselho Nacional de Educação. Câmara de Educação Básica. Resolução CNE/ $\overline{C E B ~ n .}{ }^{\circ} 4$, de 2 de outubro de 2009. Institui Diretrizes Operacionais para o Atendimento Educacional Especializado na Educação Básica, modalidade Educação Especial. Diário Oficial da União, 5 de outubro de 2009.

BRASIL. Conselho Nacional de Educação. Câmara de Educação Básica. Parecer CNE/CEB n..$^{\circ}$ 13/2009. Diretrizes Operacionais para o atendimento educacional especializado na Educação Básica, modalidade Educação Especial. Diário Oficial da União, 25 de setembro de 2009.

BRIZOLLA, F. Políticas públicas de inclusão escolar: 'negociação sem fim'. 2007. Tese (Doutorado) - Faculdade de Educação. Programa de Pós-Graduação em Educação. Universidade Federal do Rio Grande do Sul, Porto Alegre, 2007.

BÜRKLE, T. S. A Sala de Recursos como suporte à Educação Inclusiva no Município do Rio de Janeiro: das propostas legais à prática cotidiana. 2010. 147f. Dissertação (Mestrado) Faculdade de Educação, Universidade do Estado do Rio de Janeiro, Rio de Janeiro. 2010.

CARVALHO, R. E. A Política de Educação Especial no Brasil. Em Aberto, Brasília, v.13, n.60, p.93-102, 1993.

CORREAA, N. M. O Programa de Implantação de Salas de Recursos Multifuncionais e o Plano de Ações Articuladas (PAR): uma análise da rede municipal de ensino de Campo Grande - MS. In: SEMINÁRIO NACIONAL DE PESQUISA EM EDUCAÇÃO ESPECIAL. Prática Pedagógica na Educação Especial: multiplicidade do atendimento educacional especializado, 4., 2011, Nova Almeida. Anais... Nova Almeida, 2011. 1 CD-ROM.

DELEVATI, A. C. AEE: que "atendimento" é este? As configurações do Atendimento Educacional Especializado na perspectiva da rede municipal de ensino de Gravataí - RS. 2011. 43f. Projeto de Dissertação de Mestrado - Faculdade de Educação, Programa de PósGraduação em Educação, Universidade Federal do Rio Grande do Sul, Porto Alegre, 2011.

FERREIRA, J.; NUNES, L. Deficiência mental: o que as pesquisas brasileiras têm revelado. Em Aberto, n.60, p.37-60, 1993. 
BAPTISTA, C. R.

FREITAS, C. R. Corpos que não param: criança, "TDAH" e escola. 2011. 191f. Tese (Doutorado em Educação) - Faculdade de Educação, Programa de Pós-Graduação em Educação, Universidade Federal do Rio Grande do Sul. Porto Alegre, 2011.

KASSAR, M. C. M.; REBELO, A. S. O “especial” na educação, o atendimento especializado e a educação especial. In: SEMINÁRIO NACIONAL DE PESQUISA EM EDUCAÇÃO ESPECIAL. Prática Pedagógica na Educação Especial: multiplicidade do atendimento educacional especializado, 4., 2011, Nova Almeida. Anais... Nova Almeida, 2011. CD-ROM.

MAZZOTTA, M. J. S. Fundamentos da educação especial. São Paulo: Pioneira, 1982.

OLIVEIRA, F. M. G. S. As salas de recursos como apoio pedagógico especializado à educação escolar do deficiente mental. 2004. 140f. Dissertação (Mestrado) - Programa de Pós-Graduação em Educação, Universidade Federal do Mato Grosso do Sul, Campo Grande, 2004.

PRIETO, R. G.; SOUSA, S. M. Z. L.; SILVA, M. C. Educação especial no município de São Paulo: Acompanhamento da trajetória escolar de alunos no ensino regular. In: REUNIÃO ANUAL DA ASSOCIAÇÃO NACIONAL DE PÓS-GRADUAÇÃO EM PESQUISA E EDUCAÇÃO, 2006, Caxambu. Anais Eletrônicos... Caxambu: 2006 , ANPED, GT15. Disponível em: <www.anped.org.br/reunioes/27/gt15/t1511.pdf>. Acesso em: 20 jul. 2011.

PRIETO, R.. G.; SOUZA, S. M. Z. L. Educação especial: o atendimento em salas de recursos na rede municipal de São Paulo. Educação Revista do Centro de Educação. Santa Maria, v.32, n.2, p.375-396, 2007.

SANTOS JÚNIOR, F. D. As políticas de educação especial na Rede Municipal de Ensino de Porto Alegre: 1989-2000. 2002. 174 f. Dissertação (Mestrado em Educação Especial) - Faculdade de Educação, Programa de Pós-Graduação em Educação, Universidade Federal do Rio Grande do Sul, Porto Alegre, 2002.

SCHNEIDER, F. C.; PASSERINO, L. M. Ser freqüentador de uma Sala de Integração e Recursos. In: SEMANA DE EXTENSÃO, PESQUISA E PÓS-GRADUAÇÃO DO UNIRITTER, 6., 2010, Porto Alegre. Anais Eletrônicos... Porto Alegre: UNIRITTER, 2010. Disponível em: <www.uniritter.edu.br/eventos/sepesq/ vi_sepes /.../ 27979 /.../ comide.pdf>. Acesso em: 20 jul. 2011.

SILVA, M. F. N. Encaminhamento de alunos para salas de recursos: análise sobre os argumentos apresentados por professores de classes comuns. 2010. 139f. Dissertação (Mestrado em Psicologia e Educação) - Faculdade de Educação, Programa de PósGraduação em Educação, Universidade de São Paulo, São Paulo, 2010.

SILVA, S. C.; MONTEIRO, F. M. A. Formação de Professores de Sala de Recursos e a Educação Especial em Mato Grosso: Contexto e Percurso. In: SEMINÁRIO DE EDUCAÇÃO: Políticas educacionais: cenários e projetos sociais, 2009, 17., Mato Grosso. Anais Eletrônicos... Mato Grosso: UFMT, 2009. Disponível em: <www.ie.ufmt.br/ semiedu2009/gts/gt10/ComunicacaoOral/v.pdf>. Acesso em: 20 jul. 2011

SOARES, C. H. R. Inclusão, Surdez e Ensino Médio: perspectivas e possibiliades para o Atendimento Educacional Especializado. 2011. 96f. Dissertação (Mestrado em Educação) - Faculdade de Educação, Programa de Pós-Graduação em Educação, Universidade Federal do Rio Grande do Sul, Porto Alegre, 2011.

TEZZARI, M. L. "A SIR chegou..." Sala de Integração e Recursos e a Inclusão na Rede Municipal de Ensino em Porto Alegre. 2002. 182f. Dissertação (Mestrado em Educação) 
Ação pedagógica e Educação Especial

- Faculdade de Educação, Programa de Pós-Graduação em Educação, Universidade Federal do Rio Grande do Sul. Porto Alegre, 2002.

TEZZARI, M. L; BAPTISTA, C. R. Vamos brincar de Giovani? A integração escolar e o desafio da psicose. In: BAPTISTA, C. R; BOSA, C. (Org.). Autismo e Educação: reflexões e propostas de intervenção. Porto Alegre: Artmed, 2002. p.145-156.

Recebido em: 21/07/2011

Aceito em: 30/08/2011 